\title{
ANÁLISE ECONÔMICA DO CULTIVO E EXTRAÇÃO DO ÓLEO ESSENCIAL DE Melaleuca alternifolia Cheel ${ }^{1}$
}

Ciro de Castro² Márcio Lopes da Silva $^{3}$, Antônio Lelis Pinheiro ${ }^{3}$ e Laércio Antônio Gonçalves Jacovine ${ }^{3}$

\begin{abstract}
RESUMO - Este trabalho estudou a viabilidade econômica do cultivo e extração do óleo essencial de um plantio de Melaleuca alternifolia Cheel. Foi realizado um levantamento dos rendimentos e custos da cultura das atividades de produção de mudas, implantação, manutenção, colheita, transporte e extração do óleo essencial, bem como as receitas. A análise econômica foi realizada utilizando-se os seguintes indicadores econômicos: Valor Presente Líquido, Razão Benefício/Custo, Taxa Interna de Retorno, Valor Anual Equivalente e Custo Médio de Produção. Posteriormente foi feita uma análise de sensibilidade, utilizando-se a técnica de simulação de Monte Carlo, por meio do software @Risk. Uma vez reunidos e analisados os dados, fixaram-se parâmetros mínimos, médios e máximos para as distribuições de probabilidade triangular dos custos de implantação, manutenção, colheita, destilação e da receita, oriundos do projeto de produção do óleo essencial, permitindo uma melhor avaliação dos indicadores econômicos perante a análise de riscos. Como resultado, obteve-se um rendimento de 81,82 $\mathrm{L}$ de óleo essencial por ha por ano, conseqüentemente um lucro anual de $\mathrm{R} \$ 497,18$ por hectare, enquanto a análise de sensibilidade apresentou uma baixa probabilidade de a atividade tornar-se inviável economicamente.
\end{abstract}

Palavras-chave: Melaleuca, análise econômica e óleo essencial.

\section{ECONOMIC ANALYSIS OF THE CULTIVATION AND EXTRACTION OF THE ESSENTIAL OIL OF Melaleuca alternifolia Cheel}

\begin{abstract}
This paper describes the study of the economic viability of cultivation and essential oil extraction of Melaleuca alternifolia Cheel. An assessment was made of profits and costs for activities of seedling production, implantation, maintenance, harvesting, transport and essential oil extraction, as well as revenues. The economic analysis was accomplished using the following economic indicators: Net Present Value, Benefit/Cost Ratio, Internal Return Rate, Equivalent Annual Value and Average Cost of Production. Then a sensibility analysis was performed using the simulation technique of Monte Carlo - software @ Risk. Once data were collected and analyzed, minimum, medium and maximum parameters for triangular probability distribution of implantation, maintenance, harvest, distillation and revenue costs were fixed, derived from the project of essential oil production, allowing a better evaluation of economic indicators before the risk analysis. As result a productivity of 81.82 $L$ essential oil ha $a^{-1}$ year-1 was achieved with an annual profit of $R \$ 497,18$ per hectare, whereas the sensibility analysis gave a low probability for the activity to become economically unviable.
\end{abstract}

Key Words: Tea Tree, economic analysis and essential oil.

\footnotetext{
${ }^{1}$ Recebido em 05.03.2004 e aceito para publicação em 25.11.2004.

${ }^{2}$ Eng. Florestal.

${ }^{3}$ Departamento de Engenharia Florestal da UFV. E-mail: <marlosil@ufv.br>.
} 


\section{INTRODUÇÃOO}

A melaleuca (Melaleuca alternifolia Cheel), conhecida internacionalmente como Tea Tree, é uma espécie arbórea da família Myrtaceae. Seu principal produto é o óleo essencial, de grande importância medicinal, pelo fato de possuir comprovada ação bactericida e antifúngica contra vários patógenos humanos, sendo utilizado em muitas formulações tópicas; é obtido por hidrodestilação ou destilação por arraste a vapor (RIEDL, 1997; GUSTAFSON et al., 1998).

Essa espécie ocorre naturalmente na Austrália, onde se concentram os principais produtores, que dominam, de certa forma, o mercado e as tecnologias de produção, sendo ela o principal fornecedor mundial desse óleo (aproximadamente 400 t/ano). Têm-se relatos de que a China também produz o óleo, porém em escala não-significativa perante o mercado mundial. O consumo desse óleo está disperso no mundo inteiro pelas indústrias (farmacêuticas, de cosméticos e de limpeza, dentre outras), sendo os principais centros consumidores América do Norte e Europa.

O preço desse óleo encontra-se, hoje, num patamar econômico mundial elevado, acreditando que isso ocorre devido ao seu monopólio comercial, o qual é produzido, até então, somente pela Austrália. No Brasil, têm-se observado indústrias de cosméticos e casa de produtos naturais, adquirindo o produto importado e repassando ao consumidor final ou, então, agregando valores ao produto em forma de cosméticos, produtos farmacêuticos e higiene pessoal.

Sendo o quinto maior consumidor mundial de remédios, o Brasil tem desenvolvido poucos medicamentos. O mercado brasileiro é dominado por multinacionais farmacêuticas que investem pesadamente em pesquisas e tecnologia para garantir espaço em um universo cujas cifras são da ordem de 200 milhões de dólares ao ano. Há possibilidade de crescimento dos fitoterápicos, que é um mercado em expansão e exibe cifras igualmente consideráveis da ordem de 40 milhões de dólares ao ano. Entretanto, não há dados concretos sobre quanto se importa de óleo essencial de melaleuca atualmente, mas sabe-se que até 2002 todo o óleo consumido era o importado. Em razão de sua imensa biodiversidade e da tradição no uso de plantas medicinais, o Brasil tem condições de reservar para si parte considerável desse mercado (OLIVEIRA, 2002).

R. Árvore, Viçosa-MG, v.29, n.2, p.241-249, 2005
Pode-se dizer que a implantação desse tipo de indústria traria para o Brasil, em primeira instância, dois benefícios sociais: um seria o auxílio na cura de doenças dermatológicas oriundas de bactérias e, ou, fungos, acreditando-se ainda que tenha propriedades antivirais; o outro seria a criação de empresas para plantio da espécie, extração do óleo essencial, beneficiamento e comercialização do óleo ou dos produtos já beneficiados, gerando empregos diretos e indiretos, impostos e divisas, uma vez que seu rendimento pode variar de 170-220 kg.ha-1 (MURTAGH, 1998).

Nesse contexto, o objetivo deste trabalho foi realizar uma análise econômica, utilizando os principais indicadores econômicos, através do levantamento dos custos e receitas do cultivo da planta e extração do óleo essencial, e também a análise de sensibilidade, por meio de simulações, considerando-se os efeitos de variações em parâmetros importantes, como o preço de venda do óleo essencial e os custos da referida produção florestal.

\section{MATERIAL E MÉTODOS}

\subsection{Caracterização da área de estudo e fonte de dados}

O presente estudo teve como fonte de dados o plantio experimental de melaleuca implantado no Sítio Colônia, localizado a $20^{\circ} 42,846^{\prime}$ S, $42^{\circ} 43.635^{\prime} \mathrm{W}, 689$ $\mathrm{m}$ de altitude, no município de São Miguel do Anta, na Zona da Mata Norte do Estado de Minas Gerais. Segundo CER/PROAGRO (2002), o município apresenta um índice pluviométrico entre 1.100 e 1.300 mm, com uma concentração de chuvas maior entre os meses de novembro e março. A temperatura média anual é de $20,9^{\circ} \mathrm{C}$, tendo uma média mínima de $14,4^{\circ} \mathrm{C}$ (julho) e uma média máxima de $26,5^{\circ} \mathrm{C}$ (fevereiro) (FUNDER, 2002).

A maioria dos dados foi obtida pelo autor acompanhando todo o processo, desde a preparação do terreno até a extração do óleo essencial, no local do experimento, sendo essas informações obtidas diretamente com o responsável técnico do projeto. Outros dados, como valor do óleo, adubos, energia elétrica, sacos plásticos, equipamento de irrigação e outros, foram obtidos no mercado de Viçosa, MG, entre os meses de abril e maio de 2002. Os valores monetários estão em real, sendo na época (abril e maio de 2003) um dólar americano equivalente a $\mathrm{R} \$ 3,00$. Outros preços 
e custos foram levantados na Internet, em publicações do setor florestal e entrevistas com técnicos da área.

\subsection{Descrição das atividades}

O ano zero foi o período correspondente ao início das atividades (2001), por exemplo elaboração e planejamento do projeto, locação da área de plantio, locação e construção do viveiro, produção de mudas, preparo do solo, adubação, correção do solo, coveamento, combate às formigas cortadeiras e plantio propriamente dito. A área foi preparada para o plantio de mudas de melaleuca, no espaçamento de 1 x 1 m (10.000 árvores por hectare), compreendendo uma área de 0,5 ha. É necessário observar que as planilhas apresentadas neste estudo estão todas em base de 1 ha, pois este foi o parâmetro adotado para a formação de custos.

O início da atividade de produção de mudas deuse em novembro de 2001. Esse mês foi escolhido com base no fato de a cultura ser extremamente exigente em água. Como é nessa época que a região tem maior índice pluviométrico médio mensal, foi necessária, então, pouca irrigação durante o processo de produção das mudas. Para essa atividade foram necessárias aproximadamente 932 horas-homem. Esse custo foi considerado dentro dos custos de implantação e manutenção, como aquisição de mudas.

A operação de adubação e correção do solo foi conduzida de forma a prepará-lo quimicamente para que pudesse receber a nova cultura. O preparo consistiu na aração, com arado de disco acoplado ao trator, seguida de gradagem niveladora do terreno, para que, dessa forma, fosse homogeneizada a adubação, aplainada a superfície do solo e realizada, assim, uma limpeza prévia da área, 15 dias antes do plantio.

O coveamento foi realizado no momento do plantio, em março de 2002, utilizando o sistema manual. As covas tiveram as dimensões de 0,40 × 0,40 x 0,40 m, valor baseado nas covas de café utilizadas por produtores locais. Nos plantios recentes estão sendo usadas covas de $0,20 \times 0,20 \times 0,20 \mathrm{~m}$, o que leva a crer que melhores resultados poderão ser obtidos, pois se espera reduzir o custo da mão-de-obra necessária para a realização de tal tarefa, em comparação com o utilizado neste estudo, que resultou em 160 horas/homem ${ }^{-1}$ efetivas de trabalho para essa operação.

Foi realizada irrigação diária durante uma semana após o plantio; depois, passou-se a utilizar a irrigação de dois em dois dias por mais uma semana e, posteriormente, com uma freqüência de duas a três irrigações por semana, dependendo, logicamente, da necessidade. O replantio foi realizado 15 dias após o plantio.

Para o controle de plantas invasoras pós-plantio foi utilizada apenas a capina manual em maio de 2002 ( 2 meses pós-plantio), totalizando 80 horas/homem para a realização dessa operação. Teve-se cuidado com o controle de formigas durante todo o processo de plantio, como também no processo de manutenção. Foi observado durante todo o período que a cultura demonstrou pouca atratividade por formigas, em comparação com a cultura do eucalipto. Acredita-se que essa baixa atratividade seja devida à concentração do óleo essencial, que tem como características básicas ser bactericida e antifungicida.

A manutenção, nesse sistema de cultivo, é considerada um conjunto de atividades envolvidas na condução do povoamento, podendo ocorrer periodicamente ou não, dentro do horizonte de planejamento. Essas atividades foram consideradas temporalmente entre a capina pós-plantio (maio de 2002) e o início da primeira colheita (agosto de 2002), para um primeiro estágio, e a partir daí, tidas como o período entre duas colheitas, sendo, então, quatro meses, em média, para cada período. É interessante observar que esse processo é cíclico, quatro em quatro meses, em média, do ano 1 ao 10, perfazendo, assim, 30 ciclos de manutenção até a reforma completa do povoamento. As operações de manutenção propriamente ditas são as seguintes: adubações mineral e orgânica, desbrota, irrigação, controle de formigas cortadeiras e reforma parcial.

Têm-se, para o cultivo da melaleuca, três colheitas anuais, sendo o ciclo médio de corte da cultura de quatro meses, efetuado do ano 1 ao 10 , ou seja, durante todo o período de manutenção da cultura. Segundo Silva (2001), a colheita propriamente dita deve ser efetuada pela manhã, antes das $10 \mathrm{~h}$, para se obter maior rendimento. Faz-se, com um facão, um corte em bisel, no tronco, a aproximadamente $5-10 \mathrm{~cm}$ de altura do solo. É necessário salientar que a colheita deve ser realizada no mesmo dia em que a planta será processada (beneficiada). Por isso, deve-se tomar o cuidado para colher somente a quantidade necessária ao beneficiamento diário. Logo após o corte, esse material

R. Árvore, Viçosa-MG, v.29, n.2, p.241-249, 2005 
é transportado, numa carroça, para o local de beneficiamento.

Tão logo as plantas chegam "do campo", esse material é colocado em triturador orgânico para que aumente a superfície de contato das folhas, permitindo, assim, o melhor rendimento na destilação. Outro bom motivo para que as folhas sejam trituradas é uma melhor acomodação do material vegetal dentro do destilador. Depois de triturado, o material é colocado em sacos plásticos de $10 \mathrm{~kg}$ e fechado para que, até o momento da destilação, esse material conserve as características ideais ao processo.

O processo de destilação utilizado é por arraste de vapor, ou seja, consiste em colocar o material vegetal no destilador, que, por arraste de vapor, extrai-se o óleo que é conduzido para o sistema de condensação e coletado em um recipiente de decantação. Após 1h30, o material vegetal é removido do destilador, pois a maior parte do óleo já foi extraída. Para geração do vapor, utilizou-se uma caldeira à lenha.

No recipiente de decantação, a água separa-se, naturalmente, do óleo. O excesso de água é retirado do recipiente através de uma torneira. Quando a quantidade de óleo se torna tanta a ponto de não permitir mais a continuidade do processo, passa-se, então, o mesmo para o funil de decantação, para que haja uma separação minuciosa da água e do óleo. Posteriormente, esse óleo é envasado em vidro âmbar e mantido em local abrigado de temperatura e luminosidade. É interessante ressaltar que toda a água extraída do processo de destilação é armazenada, pois, pelo fato de conter, em média, $2 \%$ de óleo emulsificado em sua constituição, pode ser utilizada pela indústria. As folhas residuais do processo de destilação são usadas para adubação orgânica.

\subsection{Análise de rendimentos}

Para o rendimento do processo de destilação foram determinados o volume de óleo essencial por $\mathrm{kg}$ de material vegetal e, conseqüentemente, o volume de óleo essencial por área e volume de água residual do processo de destilação por kg de material vegetal. Foi necessário, para isso, conhecer o rendimento das máquinas e da mão-de-obra e o custo unitário. Foram levantados os principais custos com máquinas, mãode-obra e insumos, relacionados com a produção de mudas, implantação, manutenção, colheita e beneficiamento do povoamento.

R. Árvore, Viçosa-MG, v.29, n.2, p.241-249, 2005

\subsection{Análise econômica}

De posse dos rendimentos e custos dos insumos e fatores de produção foi possível chegar-se aos custos por atividade da cultura, por meio da confecção de planilhas de custo. Posteriormente, utilizaram-se os seguintes critérios para análise econômica de projetos, conforme Rezende e Oliveira (2001):

a) Valor Presente Líquido (VPL)

$$
V P L=\sum_{j=0}^{n} R_{j}(1+i)^{-j}-\sum_{j=0}^{n} C_{j}(1+i)^{-j}
$$

b) Valor Anual Equivalente (VAE)

$$
V A E=\frac{V P L . i}{1-(1+i)^{-n}}
$$

c) Taxa Interna de Retorno (TIR)

$$
\sum_{j=0}^{n} R_{j}(1+T I R)^{-j}=\sum_{j=0}^{n} C_{j}(1+T I R)^{-j}
$$

d) Custo Médio de Produção (CMPr)

$$
C M P=\frac{\sum_{j=0}^{n} C T_{j}(1+i)^{-j}}{\sum_{j=0}^{n} P T_{j}(1+i)^{-j}}
$$

e) Razão Benefício/Custo (B/C)

$$
B / C=\frac{\sum_{j=0}^{n} R_{j}(1+i)^{-j}}{\sum_{j=0}^{n} C_{j}(1+i)^{-j}}
$$

Os termos são: $\mathrm{Rj}=$ valor atual das receitas, $\mathrm{R} \$ . \mathrm{ha}^{-1} ; \mathrm{Cj}=$ valor atual dos custos, $\mathrm{R} \$ . \mathrm{ha}^{-1} ; \mathrm{i}=$ taxa de juros; $\mathrm{j}$ = período em que a receita ou custo ocorre; $\mathrm{n}=$ número máximo de períodos $; \mathrm{CT}_{\mathrm{j}}=$ custo total, $\mathrm{R} \$ \cdot \mathrm{ha}^{-1} ; \mathrm{e} \mathrm{PT}_{\mathrm{j}}=$ produção total, litros.ha- $\mathrm{h}^{-1}$.

\subsection{Análise de sensibilidade}

As simulações realizadas neste trabalho foram efetuadas no software @ Risk, utilizando-se o Método de Monte Carlo, distribuição de probabilidade estratificada, denominada Latin Hipercub, através de 10.000 iterações, visando permitir introduzir o risco na análise a ser efetuada, conforme Noronha (1987) e Rodriguez (1987). 
Foram consideradas variáveis de entrada (inputs) as seguintes: receita anual, custo de implantação, custo de manutenção, custo de colheita e custo de extração.

Para definir os valores mínimos, médios e máximos das variáveis de entrada, considerou-se uma variação de $-20 \%$ a $+20 \%$ do valor-base dessas, com exceção da receita anual, a qual foi de $-20 \% \mathrm{a}+100 \%$. Optouse por esse valor máximo em virtude de a produção ter atingido tal variação no processo de destilação do óleo.

Foram considerados variáveis de saída (outputs) os seguintes indicadores econômicos: TIR, VPL, CMPr, VAE e B/C, sendo obtidos os valores mínimos, médios e máximos, desvio-padrão e percentis das variáveis de entrada e saída. Também foram obtidas as elasticidades (obtidas por meio dos coeficientes de regressão linear múltipla), que evidenciaram a sensibilidade das variáveis de entrada nos resultados.

\section{RESULTADOS E DISCUSSÃO}

\subsection{Custos das operações}

No Quadro 1, apresenta-se o custo das operações necessárias à implantação (ano 0) de 1 ha de melaleuca, plantada no espaçamento de 1 x 1 m (10.000 árv.ha-1).
Observa-se, nesse quadro, que o custo total de implantação ficou em R \$3.016,71.ha $\mathrm{h}^{-1}$. ano ${ }^{-1}$, sendo as participações dos custos com máquinas, mão-de-obra e insumos, respectivamente, de 17, 32 e 52\%.

No Quadro 2 é apresentado o custo das operações necessárias à manutenção de 1 ha de melaleuca, plantada no espaçamento de 1 x $1 \mathrm{~m}$ (10.000 árv.ha $\left.{ }^{-1}\right)$. Observase, nesse quadro, que o custo total de manutenção ficou em R $\$ 6.909,09$. ha $^{-1}$.ano ${ }^{-1}$, sendo as participações dos custos com máquinas, mão-de-obra e insumos 33, 48 e $19 \%$, respectivamente. Os gastos com irrigação e capina foram os itens que mais contribuíram para a elevação do custo de manutenção do projeto, representando 31 e $27 \%$, respectivamente, do custo total do processo.

No Quadro 3, apresentam-se o rendimento e o custo das operações necessárias à colheita de 1 ha de Melaleuca alternifolia, plantada no espaçamento de 1 x $1 \mathrm{~m}$ (10.000 árv.ha $\left.{ }^{-1}\right)$. Observa-se, nesse quadro, que o custo total da colheita ficou em $\mathrm{R} \$ 961,36$.ha1.ano-1, sendo as participações dos preços de máquinas e da mão-de-obra 20 e $80 \%$, respectivamente. Observase também que $55 \%$ desses gastos foram referente ao processo de transporte, $28 \%$ ao corte e o restante (17\%) aos custos administrativos.

Quadro 1 - Custo das operações necessárias à implantação (ano 0) de um hectare de Melaleuca alternifolia Cheel, plantada no espaçamento de 1 x $1 \mathrm{~m}$ (10.000 árv.ha $\left.{ }^{-1}\right)$

Table 1 - Operational Costs for the implantation (year 0$)$ of one hectare $1 \times 1 \mathrm{~m}$ spacing $\left(10,000\right.$ plants. ha $\left.{ }^{-1}\right)$ of Melaleuca alternifolia Cheel

\begin{tabular}{lcccc}
\hline OPERAÇÃO & $\begin{array}{c}\text { Máquinas } \\
(\mathrm{R} \$ / \mathrm{ha})\end{array}$ & $\begin{array}{c}\text { Mão-de-obra } \\
(\mathrm{R} \$ / \mathrm{ha})\end{array}$ & $\begin{array}{c}\text { Insumos } \\
(\mathrm{R} \$ / \mathrm{ha})\end{array}$ & $\begin{array}{c}\text { Total } \\
(\mathrm{R} \$ / \mathrm{ha})\end{array}$ \\
\hline Capina manual pré-plantio & - & 128,00 & - & 128,00 \\
Aração e gradagem & 140,00 & - & - & 140,00 \\
Aplicação de adubo & - & 19,20 & 229,00 & 248,20 \\
Aplicação de esterco & - & 25,60 & 384,00 & 425,60 \\
Aplicação de calcário & - & 19,20 & 30,00 & 61,20 \\
Combate às formigas & - & 12,80 & 25,20 & 38,00 \\
Coveamento (40 x 40 x 40 cm) & - & 256,00 & - & 256,00 \\
Transporte de mudas & - & 6,40 & - & 6,40 \\
Distribuição e plantio de mudas & - & 182,86 & 400,00 & 747,86 \\
Reposição de mudas defeituosas & - & 1,83 & 4,00 & 7,48 \\
Replantio & - & 9,14 & 20,00 & 37,39 \\
Capina manual & & 128,00 & - & 128,00 \\
Irrigação & 261,00 & 14,40 & - & 289,80 \\
Custo administrativo $(20 \%)$ & 83,08 & 160,69 & 259,02 & 502,79 \\
Custo final (R\$/ha) & 498,48 & 964,11 & $1.554,12$ & $3.016,71$ \\
\hline
\end{tabular}


Quadro 2 - Custo das operações necessárias à manutenção (ano 1-10) de um hectare de Melaleuca alternifolia Cheel plantado no espaçamento de 1 x $1 \mathrm{~m}\left(10.000\right.$ árv.ha $\left.{ }^{-1}\right)$

Table 2 - Operational costs for the maintenance (year 1-10) of one hectare $1 \times 1 \mathrm{~m}$ spacing (10,000 plants. ha - $\left.^{-1}\right)$ of Melaleuca alternifolia Cheel

\begin{tabular}{lcccc}
\hline OPERAÇÃO & $\begin{array}{c}\text { Máquinas } \\
(\mathrm{R} \$ / \mathrm{ha})\end{array}$ & $\begin{array}{c}\text { Mão-de-obra } \\
(\mathrm{R} \$ / \text { há })\end{array}$ & $\begin{array}{c}\text { Insumos } \\
(\mathrm{R} \$ / \mathrm{ha})\end{array}$ & $\begin{array}{c}\text { Total } \\
(\mathrm{R} \$ / \mathrm{ha})\end{array}$ \\
\hline Reforma parcial & - & 30,00 & 30,00 & 72,38 \\
Aplicação de esterco & - & 76,80 & 480,00 & 556,80 \\
Desbrota & - & 153,60 & - & 153,60 \\
Capina manual & - & 2457,60 & - & $2.457,60$ \\
Combate às formigas & 1903,20 & 38,40 & 75,60 & 114,00 \\
Irrigação & & - & - & $1.903,20$ \\
Custo da terra & 380,64 & 551,28 & 219,59 & - \\
Custo administrativo (20\%) & $2.283,84$ & $3.307,68$ & $1.317,57$ & $1.151,52$ \\
Custo final (R\$/ha/ano) & & & & $6.909,09$ \\
\hline
\end{tabular}

Quadro 3 - Custo das operações necessárias à colheita (ano 1-10) de um hectare de Melaleuca alternifolia Cheel, plantado no espaçamento de 1 x $1 \mathrm{~m}\left(10.000\right.$ árv.ha $\left.{ }^{-1}\right)$

Table 3 - Operational Costs for the harvest (year 1-10) of one hectare $1 \times 1 \mathrm{~m}$ spacing (10,000 plants.ha $\left.{ }^{-1}\right)$ of Melaleuca alternifolia Cheel

\begin{tabular}{lccc}
\hline OPERAÇÃO & Máquinas & Mão-de-obra & Total \\
$(\mathrm{R} \$$ \$ha $/$ ha $)$ & 272,73 & 272,73 \\
\hline Corte & - & 272,73 & 528,41 \\
Transporte & 255,68 & 109,09 & 160,23 \\
Custo administrativo (20\%) & 51,14 & 654,55 & 961,36 \\
Custo final (R\$/ha/ano) & 306,82 & \\
\hline
\end{tabular}

No Quadro 4, apresenta-se o custo das operações necessárias ao beneficiamento do óleo essencial, extraído de 1 ha de Melaleuca alternifolia. Observa-se, nesse quadro, que o custo total do beneficiamento ficou em $\mathrm{R} \$ 3.414,13 \cdot$ ha $^{-1} \cdot$ ano $^{-1}$, sendo as participações dos custos com máquinas, mão-de-obra e insumos 35, 48 e 17\%, respectivamente. Os maiores gastos foram os da destilação propriamente dita e os de abastecimento da caldeira. No Quadro 5, tem-se que os preços de mão-de-obra para triturar o material vegetal mais o da embalagem, energia elétrica e madeira necessária à geração de vapor foram, respectivamente, 32,1 e $13 \%$, ou seja, $46 \%$ dos custos totais desse processo.

Quadro 4 - Custo das operações necessárias à extração (ano 1-10) de um hectare de Melaleuca alternifolia Cheel, plantado no espaçamento de 1 x $1 \mathrm{~m}(10.000$ árv.ha-1)

Table 4 -Operational Costs for the extration (year 1-10) of one hectare $1 \times 1 \mathrm{~m}$ spacing (10,000 plants.ha $\left.\mathrm{a}^{-1}\right)$ of Melaleuca alternifolia Cheel

\begin{tabular}{lcccc}
\hline OPERAÇÃO & $\begin{array}{c}\text { Máquinas } \\
(\mathrm{R} \$ / \mathrm{ha})\end{array}$ & $\begin{array}{c}\text { Mão-de-obra } \\
(\mathrm{R} \$ / \mathrm{ha})\end{array}$ & $\begin{array}{c}\text { Insumos } \\
(\mathrm{R} \$ / \mathrm{ha})\end{array}$ & $\begin{array}{c}\text { Total } \\
(\mathrm{R} \$ / \mathrm{ha})\end{array}$ \\
\hline Trituração + destilação & - & $1.090,91$ & 18,55 & $1.109,46$ \\
Abastecimento da caldeira anual & - & 272,73 & 456,57 & 729,30 \\
Custos fixos anuais & 506,35 & & & 506,35 \\
Reparos anuais & 500,00 & & & 500,00 \\
Custo administrativo (20\%) & 201,27 & 272,73 & 95,02 & 569,02 \\
Custo final (R\$/ha/ano) & $1.207,62$ & $1.636,36$ & 570,15 & $3.414,13$ \\
\hline
\end{tabular}

R. Árvore, Viçosa-MG, v.29, n.2, p.241-249, 2005 
O Quadro 5 contém o resumo dos custos mencionados anteriormente, evidenciado-se a época de ocorrência de cada operação.

\subsection{Produção e receita do projeto}

A produção média anual de óleo essencial de melaleuca foi de $81,818 \mathrm{~L}$ por ha, a partir de aproximadamente $48 \mathrm{t}$ de material vegetal destilado. Foram produzidos, em média, $150 \mathrm{~mL}$ de óleo essencial por dia, a partir de cerca de $88 \mathrm{~kg}$ de material vegetal.

Nessa análise foi considerado apenas o óleo essencial como único produto do beneficiamento, mas posteriormente já é esperada a comercialização da água residual da destilação, que contém $2 \%$ de óleo essencial emulsificado. Está sendo levado em conta aqui a receita constante até o fim do projeto, já que as plantas passam por um processo gradual de replantio à medida que é necessário. O preço de comercialização do óleo essencial foi de R \$150,00 por litro.

\subsection{Análise econômica}

Observa-se, no Quadro 6, que o valor presente dos custos totais do projeto foi $\mathrm{R} \$ 72.355,62$ e o valor presente da receita total, $\mathrm{R} \$ 75.410,60$. Portanto, o VPL foi de R\$3.054,98, apresentando-se viável.

No Quadro 7, apresenta-se o resultado econômico dos diferentes critérios para o projeto de produção de óleo essencial de melaleuca. Observa-se, nesse qudro, que todos os critérios mostraram alta viabilidade da atividade. A B/C de 1,04 indica que as receitas descontadas foram $4 \%$ superiores aos custos descontados. O CMPr de $\mathrm{R} \$ 143,92$ por litro indica que este seria o preço mínimo de venda do produto para que não haja prejuízo. Dessa forma, pode-se calcular o lucro médio por litro que é de R \$7,08. A TIR de 30\% ao ano indica uma boa rentabilidade anual do capital investido no projeto. Esse valor, comparado com o de outros projetos florestais, deve-se ao saldo negativo somente no ano 0, e a partir daí saldos positivos até o término do projeto. O VAE de $\mathrm{R} \$ 497,18 \cdot \mathrm{ha}^{-1}$. ano $^{-1}$ indica o lucro anual do projeto.

\subsection{Análise de sensibilidade}

Com base no Quadro 8, observa-se que os valores médios foram de $152 \%$ ao ano, $\mathrm{R} \$ 22.845,32 . \mathrm{ha}^{-1}$, $\mathrm{R} \$ 3.713,90 \cdot \mathrm{ha}^{-1}$.ano ${ }^{-1}, \mathrm{R} \$ 118,53$ por litro e 1,32 para TIR, VPL, VAE, CMPr e B/C, respectivamente, indicando, assim, uma alta viabilidade do projeto.

Quadro 5 - Componentes do custo total de produção do óleo essencial de melaleuca e sua ocorrência ao longo dos anos

Table 5 - Total cost components of melaleuca essential oil production and its occurrence along the years

\begin{tabular}{lcc}
\hline Itens de custo & $\begin{array}{c}\text { Ano de } \\
\text { ocorrência }\end{array}$ & $\begin{array}{c}\text { Custo } \\
\left(\mathrm{R} \$ \cdot \mathrm{ha}^{-1} \cdot \mathrm{ano}^{-1}\right)\end{array}$ \\
\hline Implantação & 0 & $3.016,71$ \\
Manutenção & $1-10$ & $6.909,09$ \\
Colheita & $1-10$ & 961,36 \\
Extração & $1-10$ & $3.414,13$ \\
\hline
\end{tabular}

Quadro 6 - Atividades com os respectivos custos, receitas e lucros anuais descontados ao longo dos anos Table 6 - Activities, with the respective annual costs, revenues and profits discounted along the years

\begin{tabular}{llccc}
\hline Ano & Procedimento & Custo Desc.(R\$) & Receita Desc.(R\$) & Lucro Desc.(R\$) \\
\hline 0 & Implantação & 3016,71 & - & $-3016,71$ \\
1 & Manutenção, colheita e beneficiamento & 10258,72 & 11157,02 & 898,31 \\
2 & Manutenção, colheita e beneficiamento & 9326,11 & 10142,75 & 816,64 \\
3 & Manutenção, colheita e beneficiamento & 8478,28 & 9220,68 & 742,40 \\
4 & Manutenção, colheita e beneficiamento & 7707,52 & 8382,44 & 674,91 \\
5 & Manutenção, colheita e beneficiamento & 7006,84 & 7620,40 & 613,56 \\
6 & Manutenção, colheita e beneficiamento & 6369,86 & 6927,63 & 557,78 \\
7 & Manutenção, colheita e beneficiamento & 5790,78 & 6297,85 & 507,07 \\
8 & Manutenção, colheita e beneficiamento & 5264,34 & 5725,32 & 460,97 \\
9 & Manutenção, colheita e beneficiamento & 4785,77 & 5204,83 & 419,07 \\
10 & Manutenção, colheita e beneficiamento & 4350,70 & 4731,67 & 380,97 \\
\hline Total & & $72.355,62$ & $75.410,60$ & $3.054,98$ \\
\hline
\end{tabular}


Quadro 7 - Análise econômica do projeto de produção de óleo essencial de melaleuca

Table 7 - Economic analysis of the project of essential oil production of melaleuca

\begin{tabular}{lccc}
\hline Critério Econômico & Sigla & Valor & Unidade \\
\hline Razão Benefício/Custo & $\mathrm{B} / \mathrm{C}$ & 1,04 & - \\
Custo Médio de Produção & $\mathrm{CMPr}$ & 143,92 & $\mathrm{R} \$ .^{-1}$ \\
Taxa Interna de Retorno & TIR & 30,46 & $\%$ ao ano \\
Valor Anual Equivalente & VAE & 497,18 & $\mathrm{R} \$ \cdot \mathrm{ha}^{-1} \cdot \mathrm{ano}^{-1}$ \\
Valor Presente Líquido & VPL & $3.054,98$ & $\mathrm{R} \$ \cdot \mathrm{ha}^{-1}$ \\
\hline
\end{tabular}

Observa-se, no Quadro 9, o efeito de cada variável de entrada nos indicadores econômicos. Os valores positivos da elasticidade indicam que a relação entre as variáveis é diretamente proporcional. Por exemplo, um aumento de $10 \%$ na receita média anual acarreta aumento de 9,8\% no VPL. No entanto, um aumento de $10 \%$ no custo médio de implantação acarreta uma diminuição de 1,3\% no valor do VPL. Observa-se também, nesse quadro, o "ranking" (R), ou seja, a ordem em que cada variável de entrada afeta os indicadores econômicos. Pode-se verificar, ainda, que a ordem ou "ranking" muda, dependendo do indicador econômico. Por exemplo, as variáveis que mais afetaram a TIR foram a receita anual seguida dos custos de implantação e manutenção. Já para o VPL as variáveis que mais afetaram foram a receita anual seguida dos custos de manutenção e custo de extração.

Já o "ranking" geral (RG) mostra a ordem das variáveis de entrada que mais afetam a análise como um todo. Observou-se que a receita anual é a variável que mais afeta a análise, seguida do custo de manutenção. Já a taxa de desconto anual foi a variável que menos afetou a análise.

Quadro 8 - Valores máximo, mínimo e médio, desvio-padrão para os indicadores econômicos (TIR, VPL, VAE, CMPr e $\mathrm{B} / \mathrm{C})$ e das variáveis de entrada

Table 8 -Maximum, minimum and average values, and standard deviation for the economic indicators (TIR, VPL, VAE, $C M P r$ and $B / C)$ and input variables

\begin{tabular}{|c|c|c|c|c|c|c|c|c|c|c|c|}
\hline \multirow[b]{2}{*}{ Nome } & \multicolumn{5}{|c|}{ Variáveis de Saída } & \multicolumn{6}{|c|}{ Variáveis de Entrada } \\
\hline & TIR & VPL & VAE & CMPr & $\mathrm{B} / \mathrm{C}$ & $\mathrm{CI}$ & $\mathrm{CM}$ & $\mathrm{CC}$ & $\mathrm{CD}$ & RA & TD \\
\hline Mínimo & $-0,12$ & $-17.978,29$ & $-2.899,22$ & 67,42 & 0,77 & $2.451,20$ & $5.633,26$ & 772,31 & $2.740,50$ & $9.867,27$ & $\overline{0,08}$ \\
\hline Máximo & 4,57 & $82.287,46$ & $13.350,57$ & 193,89 & 2,22 & $3.595,96$ & $8.271,05$ & $1.147,61$ & $4.053,13$ & $24.251,09$ & 0,12 \\
\hline Média & 1,52 & $22.845,32$ & $37.13,90$ & 118,53 & 1,32 & $3.017,70$ & $6.881,58$ & 961,94 & $3.401,20$ & $15.449,72$ & 0,10 \\
\hline Desvio-padrão & 1,02 & $19.744,22$ & $3.199,89$ & 24,01 & 0,28 & 247,24 & 544,46 & 80,65 & 278,28 & $3.128,15$ & 0,01 \\
\hline
\end{tabular}

CI - Custo de Implantação; CM - Custo de Manutenção Anual; CC - Custo de Colheita Anual; CD - Custo de Destilação Anual; RA - Receita Anual; e TD - Taxa de Desconto Anual.

Quadro 9 - Análise de sensibilidade por meio da elasticidade das variáveis de entrada, em relação às de saída, ranking (R) e "ranking" geral (RG)

Table 9 - Sensitivity analysis via input variable elasticity, in relation to output, ranking $(R)$ and overall ranking $(R G)$

\begin{tabular}{|c|c|c|c|c|c|c|c|c|c|c|c|}
\hline Variáveis de Entrada & TIR & $\mathrm{R}$ & VPL & $\mathrm{R}$ & VAE & $\mathrm{R}$ & CMPr & $\mathrm{R}$ & $\mathrm{B} / \mathrm{C}$ & $\mathrm{R}$ & RG \\
\hline Receita Anual & 0,887 & 1 & 0,9800 & 1 & 0,9810 & 1 & $-0,9430 *$ & 1 & 0,9660 & 1 & 1 \\
\hline Custo de Implantação & $-0,122$ & 2 & $-0,0130$ & 6 & $-0,0120$ & 6 & 0,0190 & 5 & $-0,0170$ & 5 & 5 \\
\hline Custo de Manutenção & $-0,092$ & 3 & $-0,1700$ & 2 & $-0,1710$ & 2 & 0,2290 & 2 & $-0,2220$ & 2 & 2 \\
\hline Custo de Extração & $-0,051$ & 4 & $-0,0850$ & 3 & $-0,0850$ & 3 & 0,1110 & 3 & $-0,1110$ & 3 & 3 \\
\hline Custo de Colheita & $-0,015$ & 5 & $-0,0240$ & 5 & $-0,0240$ & 4 & 0,0310 & 4 & $-0,0320$ & 4 & 4 \\
\hline Tx. Desc. Anual & - & - & $-0,0450$ & 4 & $-0,0050$ & 5 & 0,0070 & 6 & $-0,0060$ & 6 & 6 \\
\hline
\end{tabular}

\footnotetext{
${ }^{*}$ Refere-se ao efeito da produção total.
} 


\section{CONCLUSÕES}

Com base nos resultados, pode-se concluir que:

$\checkmark$ Sobre os custos anuais da cultura, o maior custo foi o de manutenção, sendo a irrigação e as capinas os componentes que mais influenciaram esse custo. $\mathrm{O}$ custo de colheita foi o que menos contribuiu no custo anual do projeto.

$\checkmark \mathrm{Na}$ análise econômica, todos os critérios (VPL, TIR, VAE, CMPr e B/C) apresentaram valores satisfatórios, indicando, com isso, a viabilidade econômica do projeto.

$\checkmark \mathrm{Na}$ análise de sensibilidade, observou-se que: o risco de o investimento apresentar-se inviável é baixo; as variáveis de entrada que mais afetaram a análise foram a receita anual e o custo de manutenção; a taxa de desconto anual foi a variável que menos afetou a análise.

$\checkmark$ A cultura apresentou um potencial de geração de emprego no meio rural, demandando 427 dias/ homem $^{-1}$ ao longo do ano em 1 ha, contribuindo, assim, para a fixação do homem no campo e a distribuição de renda.

$\checkmark$ Deve-se ressaltar que este estudo foi conduzido com observações até o $2^{\circ}$ ano do projeto. Contudo, seria interessante um acompanhamento por vários anos, a fim de se obterem valores médios para maior representatividade das variáveis de custo e produção.

$\checkmark$ A produção média diária de óleo foi de $150 \mathrm{~mL}$, mas produções de 250 a $300 \mathrm{~mL}$ ao dia foram observadas.

$\checkmark$ Neste estudo, a produção anual de óleo essencial foi de $81,8 \mathrm{~L} /$ ha, utilizando-se espaçamento de plantio de 1 x $1 \mathrm{~m}$. Com pequenos ajustes e padronizações no processo de destilação, espera-se que a produção anual atinja $136 \mathrm{~L} / \mathrm{ha}$. Com plantios mais adensados ( 1 x 0,5 m), estima-se aumentar ainda mais a produção por hectare.

\section{REFERÊNCIAS BIBLIOGRÁFICAS}

\section{COMISSÃO ESPECIAL DE \\ RECURSOS DO PROGRAMA DE \\ GARANTIA DA ATIVIDADE}

AGROPECUÁRIA - CER/PROAGRO

Disponível em: http://masrv54.agricultura.gov.br/ RNA/climatologia/Dados/Balanco_hidrico/MG/ Sao\%20_Miguel\%20_do\%20_Anta.html>. Acesso em: 25 nov. 2002.

\section{FUNDAÇÃO DE DESENVOLVIMENTO \\ REGIONAL. FUNDER. http://}

www.artnet.com.br/funder/, Acesso em 25/11/2002.

GUSTAFSON, J. E. et al. Effects of tea tree oil on Escherichia coli. Letters in Applied

Microbiology, v.26, p.194-198, 1998.

\section{MURTAGH, G.J. Rural Industries}

Research \& Development Corporation. R\&D Plan for the Tea Tree Oil

Industry 1998 - 2003. Disponível em <http:/ /www.rirdc.gov.au/pub/tto5yr.htm>. Acesso em 25/ $11 / 02$.

NORONHA, J.F. Projetos agropecuários: administração financeira, orçamento e viabilidade econômica. São Paulo: Atlas, 1987. $268 \mathrm{p}$.

OLIVEIRA, T. T. Avaliação toxicológica, caracterização de atividades biológicas, toxicologia e controle de qualidade do fitoterápico Larix. Viçosa, MG: Universidade Federal de Viçosa, 2002. 64p. (Projeto de Pesquisa).

\section{REZENDE, J.L.P.; OLIVEIRA, A.D. Análise} econômica e social de projetos

florestais. Viçosa, MG: Universidade Federal de Viçosa, 2001. 389p.

RIEDL, R. W. Pratical methods for using tea tree oil. Agro-Food Industry/Hi-Tech. Ballina, set/oct, p.34-36, 1997.

\section{RODRIGUEZ, L.C.E. Planejamento} agropecuário através de um modelo de programação linear não determinista. 1987. 83 f. Dissertação (Mestrado em Economia Agrária) - Escola Superior de Agricultura Luiz de Queiroz, Piracicaba, 1987.

SILVA, S. R. S. Composição química, avaliação da atividade antimicrobiana do óleo essencial e deficiência hídrica de Melaleuca alternifolia Cheel crescida no Brasil. 2001. 60f. Dissertação (Mestrado em Agroquímica) - Universidade Federal de Viçosa, Viçosa, 2001.

R. Árvore, Viçosa-MG, v.29, n.2, p.241-249, 2005 